EESTI NSV TEADUSTE AKADEEMIA TOIMETISED. 29. KOIDE KEEMIA. 1980, NR. 4

ИЗВЕСТИЯ АКАДЕМИИ НАУК ЭСТОНСКОП ССР. ТОМ 29 ХИмИЯ. 1980, № 4

\title{
О ПРЯМОЦЕПОЧЕЧНЫХ АЛИФАТИЧЕСКИХ СТРУКТУРАХ В ГОРЮЧЕМ СЛАНЦЕ МЕСТОРОЖДЕНИЯ «МАНДРА»
}

\author{
(Представил О. Эйзен)
}

Хорошо известно, что для гумолитов характерно наличие циклических, а для сапропелитов - прямоцепочечных структур. Если циклические структуры в гумолитах, по всей вероятности, преобладают всегда, то этого нельзя сказать об алифатических структурах в сапропелитах. В ходе катагенеза и метаморфизма, а может быть и раньше, в них возрастает доля циклических структур.

Количество и длина прямоцепочечных структур органического вещества (OB) отражаются на составе продуктов его деструкции. Для анализа более низкомолекулярных продуктов широко применяются хроматографические методы, а для анализа более высокомолекулярных - различные спектральные методы, в том числе и спектроскопия ЯMP.

Появились работы, посвященные применению спектроскопии ${ }^{1} \mathrm{H}$ ЯМР. С помощью спектров ${ }^{1} \mathrm{H}$ ЯМР были изучены продукты окислительной деструкции сапропелитов: природа алифатических структур грин-риверского сланца ['] и природа продуктов ступенчатого азотнокислотного окисления керогена кукерсита [2], а также выявлено наличие ароматических структур в диктионемовом $\left[{ }^{3}\right]$ и других сланцах $\left[{ }^{4}\right]$.

Объектом настоящего исследования является сланец месторождения «Мандра» (НР Болгария). Известно, что он. дает высокий выход смолы полукоксования - $65 \%$ от ОВ сланца [5], что продукты его окислительной деструкции содержат длинноцепочечные моно- (до $\mathrm{C}_{27}$ ) и дикарбоновые (до $\mathrm{C}_{25}$ ) кислоты $\left[{ }^{6}\right]$, а цепи $\boldsymbol{H}$-алканов низкотемпературной деструктивной гидрогенизации и полукоксования еще длиннее до $\mathrm{C}_{37}\left[{ }^{7}\right]$. В битумоиде содержатся также длинноцепочечные структуры: моно- (до $\mathrm{C}_{34}$ ) и дикарбоновые кислоты (до $\mathrm{C}_{28}$ ) и $H$-алканы (до $\left.\mathrm{C}_{34}\right)\left[{ }^{8}\right]$.

В настоящей работе делается попытка оценить количество этих прямоцепочечных структур в мандраском сланце с помощью традиционной газожидкостной хроматографии (ГЖХ), элементного анализа и спектроскопии ${ }^{1} \mathrm{H}$ ЯМР.

\section{Методика исследования}

Измельченный до 0,1 мм эоценовый сланец месторождения «Мандра» (характеристику см. в табл. 1) экстрагировали в аппарате Сокслета смесью бензола и метанола $(3: 1)$. Окислению концентрированной $\mathrm{HNO}_{3}\left(d_{4}^{20}=1,53\right)$ был подвергнут декарбонатизированный $5 \%$-ной 
Таблица 1

Характеристика сланца месторождения «Мандра» и продуктов окислительной деструкции азотной кислотой

\begin{tabular}{|c|c|c|c|c|c|c|c|c|c|}
\hline \multirow{3}{*}{ Объект исследования } & \multirow{3}{*}{$\begin{array}{c}\text { Зола, } \\
\%\end{array}$} & \multirow{3}{*}{$\begin{array}{c}\text { Выход } \\
\text { ОВ от } \\
\text { ОВ } \\
\text { сланца } \\
\%\end{array}$} & \multicolumn{4}{|c|}{ Элементный состав ОВ, \% } & \multirow{3}{*}{$\mathrm{H} / \mathrm{C}$} & \multirow{2}{*}{\multicolumn{2}{|c|}{$\begin{array}{c}\text { Выход от } \\
\text { соотв. эле- } \\
\text { мента слан- } \\
\text { ца, \% } \\
\end{array}$}} \\
\hline & & & & \multirow[t]{2}{*}{$H$} & \multirow{2}{*}{$\mathrm{N}$} & & & & \\
\hline & & & & & & & & $\mathrm{C}$ & $\mathrm{H}$ \\
\hline \multirow{2}{*}{$\begin{array}{l}\text { Исходный сланец * } \\
\text { Сланец после обработки } \\
5 \% \text {-ной } \mathrm{HNO}_{3} \\
\text { Битумоид } \\
\text { Нерастворимые продукты } \\
\text { окисления }\end{array}$} & 56,8 & 100,0 & 76,2 & 10,6 & 1,4 & 11,8 & 1,67 & 100,0 & 100 \\
\hline & $\begin{array}{c}48,6 \\
0,50\end{array}$ & $\begin{array}{r}100,0 \\
2,4\end{array}$ & $\begin{array}{l}76,3 \\
83,1\end{array}$ & $\begin{array}{l}10,5 \\
12,0\end{array}$ & & $\begin{array}{r}11,6 \\
4,3\end{array}$ & $\begin{array}{l}1,67 \\
1,73\end{array}$ & $\begin{array}{r}100,1 \\
2,6\end{array}$ & $\begin{array}{r}99, \\
2,\end{array}$ \\
\hline $\begin{array}{l}\text { окисления } \\
\text { эфирный экстракт } \\
\text { ацетоновый экстракт } \\
\text { щелочной экстракт }\end{array}$ & $\begin{array}{l}1,57 \\
1,84 \\
1,00\end{array}$ & $\begin{array}{r}18,0 \\
48,8 \\
2,7\end{array}$ & 58,6 & $\begin{array}{l}7,3 \\
5,7\end{array}$ & $\begin{array}{l}4,4 \\
5,0 \\
4,3\end{array}$ & $\begin{array}{l}29,7 \\
31,7 \\
21,5\end{array}$ & & $\begin{array}{r}13,8 \\
36,9 \\
2,3\end{array}$ & $\begin{array}{r}12,4 \\
26,2 \\
1,4\end{array}$ \\
\hline \multirow{3}{*}{$\begin{array}{l}\text { Растворимые продукты } \\
\text { окисления } \\
\text { эфирный экстракт } \\
\text { ацетоновый экстракт ** } \\
\text { высвобождающиеся при } \\
\text { обработке водой кисло- } \\
\text { ты }\end{array}$} & & & & & & & & & \\
\hline & $\begin{array}{l}0,11 \\
8,04\end{array}$ & $\begin{array}{r}18,6^{\circ} \\
9,0\end{array}$ & $\begin{array}{l}53,7 \\
15,1\end{array}$ & $\frac{7,8}{-}$ & $\underline{0,6}$ & $\stackrel{37,9}{-}$ & $\begin{array}{c}1,74 \\
(1,74)\end{array}$ & $\begin{array}{r}13,1 \\
1,8\end{array}$ & 13,7 \\
\hline & 9,97 & 3,6 & 42,4 & 6,1 & 3,6 & 47,9 & 1,73 & 2,0 & \\
\hline ром кислоты & нет & 5,2 & 39,6 & 7,2 & 1,1 & 52,1 & 2,18 & 2,7 & 3 , \\
\hline
\end{tabular}

* Минеральная углекислота $13,2 \%$, ОВ рассчнтано на основе данных обработки сланца $10 \%$-ной $\mathrm{HCl}-33,0 \%$.

** Из-за присутствия нитратов с кристаллизационной водой данные даны только по углероду, в дальнейших расчетах исходили из отношения $\mathrm{H} / \mathrm{C}$ эфирного экстракта.

азотной кислотой сланец. Загрузку сланща в кислоту осуществляли при $0-7^{\circ} \mathrm{C}$, затем температуру поднимали до $80^{\circ}$ в течение 5,5 , после чего реакционную смесь охлаждали и разбавляли водой. Растворимые и нерастворимые в слабой азотной кислоте продукты разделяли фильтрованием. Азотную кислоту и летучие с водяным паром кислоты отгоняли в вакууме. Последние выделяли из полученного дистиллята нейтрализацией, упариванием, подкислением и экстрагированием эфиром. Остаток отгонки растворимых продуктов и нерастворимые продукты сушили в вакууме и подвергали раздельно экстрагированию в аппарате Сокслета последовательно эфиром и ацетоном. Из нерастворимых продуктов окисления $1 \%$-ной щелочью был дополнительно выделен и осажден соляной кислотой щелочной экстракт, из растворимых продуктов - высвобождающиеся при обработке водой кислоты.

Средние мольмассы определялись эбуллиоскопически в ацетоне [ ${ }^{9}$, карбоксильные группы алкалиметрически в водно-ацетоновом растворе.

Содержание минеральной углекислоты сланца определяли согласно ГОСТу 6382-52, элементный анализ проводили на автоматическом анализаторе $185 \mathrm{CNH}$ фирмы Hewlett-Packard (США). Спектры ${ }^{1} \mathrm{H}$ ЯMP снимали на спектрометре BS 487 C фирмы TESLA (Чехословакия) с рабочей частотой 80 Мгц по методике [2-4]. Отнесение областей протонного поглощения продуктов окислительной деструкции сланца к его молекулярной структуре проводили согласно [2]. Углерод в метиленовых группах прямых цепей рассчитывали на основе [']. 


\section{Результаты и обсуждение}

На основе данных спектров ${ }^{1} \mathrm{H}$ ЯМР об отношении площади сигналов протонов метиленовых групп прямых цепей $\left(\mathrm{H}_{R} \sim 1,05-1,45\right.$ м. д.) к общей площади сигналов алифатических протонов (H $\sim 0,5-3,5$ м. д.) (см. табл. 2 и рисунок) и данных о количестве ионизированных протонов $\mathrm{H}_{i} / \mathrm{H}$ (табл. 2) и атомном отношении H/C (табл. 1) был рассчитан выход углерода метиленовых групп прямых цепей от общего количества углерода в продуктах окислительной деструкции (табл. 2) по формуле:

$$
\mathrm{C}_{R} / \mathrm{C}=1 / 2\left(\mathrm{H}_{R} / \mathrm{H}\right)_{N M R}\left(1-\mathrm{H}_{i} / \mathrm{H}\right) \mathrm{H} / \mathrm{C} \cdot 100, \% \text {. }
$$

Таблица 2

Распределение протонов по данным ${ }^{1}$ Н ЯМР и расчет выхода углерода и водорода прямоцепочечных структурных единиц продуктов деструкции от углерода и водорода ОВ сланца

\begin{tabular}{|c|c|c|c|c|c|c|c|c|c|}
\hline \multirow{3}{*}{ Объект исследования } & \multicolumn{5}{|c|}{ Распределение протонов, \% } & \multirow{3}{*}{$\underset{\%}{\mathrm{H}_{i} / \mathrm{H}}$} & \multirow{3}{*}{$\begin{array}{c}\mathrm{C}_{R} / \mathrm{C} \\
\%\end{array}$} & \multirow{2}{*}{\multicolumn{2}{|c|}{$\begin{array}{c}\text { Доля прямоце-- } \\
\text { почечных струк- } \\
\text { тур, \% }\end{array}$}} \\
\hline & \multirow{2}{*}{$\mathrm{CH}_{3}$} & \multirow{2}{*}{$\mathrm{CH}_{2}{ }^{*}$} & \multirow{2}{*}{$\beta-\mathrm{CH}_{2}$} & \multirow{2}{*}{$\alpha-\mathrm{CH}_{2}$} & \multirow{2}{*}{ Аром. } & & & & \\
\hline & & & & & & & & по $\mathrm{C}$ & по $\mathrm{H}$ \\
\hline Битумоид & 18 & 57 & 14 & 11 & нет & 1 & 48 & 1,3 & 1,5 \\
\hline $\begin{array}{l}\text { Нерастворимые продукты } \\
\text { эфирный экстракт } \\
\text { ацетоновый экстракт } \\
\text { щелочной экстракт }\end{array}$ & $\begin{array}{l}10 \\
13 \\
11\end{array}$ & $\begin{array}{l}35 \\
32 \\
33\end{array}$ & $\begin{array}{l}18 \\
22 \\
23\end{array}$ & $\begin{array}{l}37 \\
33 \\
33\end{array}$ & $\begin{array}{l}\text { нет } \\
\text { нет } \\
\text { нет }\end{array}$ & $\begin{array}{r}8 \\
11 \\
5\end{array}$ & $\begin{array}{l}24 \\
17 \\
21\end{array}$ & $\begin{array}{l}3,3 \\
6,3 \\
0,5\end{array}$ & $\begin{array}{l}4,3 \\
8,4 \\
0,6\end{array}$ \\
\hline $\begin{array}{l}\text { Растворимые продукты } \\
\text { эфирный экстракт } \\
\text { ацетоновый экстракт } \\
\text { высвобождающиеся при } \\
\text { обработке водой кисло- }\end{array}$ & $\begin{array}{r}10 \\
5 \\
\end{array}$ & $\begin{array}{l}29 \\
23\end{array}$ & $\begin{array}{l}26 \\
17\end{array}$ & $\begin{array}{l}35 \\
55\end{array}$ & $\begin{array}{l}\text { нет } \\
\text { нет }\end{array}$ & $\begin{array}{l}15 \\
21\end{array}$ & $\begin{array}{l}21 \\
16\end{array}$ & $\begin{array}{c}11,3^{* *} \\
0,3\end{array}$ & $\begin{array}{c}11,8^{* *} \\
0,4\end{array}$ \\
\hline $\begin{array}{l}\text { ты } \\
\text { Летучие с водяным паром }\end{array}$ & - & - & - & - & - & - & - & $1,8^{* *}$ & $1,9 * *$ \\
\hline кислоты & 18 & 36 & 22 & 22 & 2 & 17 & 32 & $1,6^{* *}$ & $2,1^{* *}$ \\
\hline $\begin{array}{l}\text { Для суммарного продукт } \\
\text { окисления }\end{array}$ & 11 & 32 & 22 & 35 & следы & 12 & 20 & 25,1 & 29,7 \\
\hline
\end{tabular}

* $\mathrm{CH}_{2}=\left(\mathrm{H}_{R} / \mathrm{H}\right)_{N M R}$.

** На основе данных ГЖХ.

таблица 3

Характеристика продуктов окислительной деструкции

\begin{tabular}{l|c|c|c}
\hline Объект исследования & $\begin{array}{c}\text { Средняя } \\
\text { моль- } \\
\text { масса }\end{array}$ & $\begin{array}{c}\text { Группа } \\
\text { МЭЮКв/2 }\end{array}$
\end{tabular}$\quad$ Средние эмпирические формулы

Нерастворимые продукты эфирный экстракт ацетоновый экстракт

Растворимые продукты эфирный экстракт высвобождаюшиеся при обработке водой кислоты
506

2630

180

152
$4,8 \quad \mathrm{C}_{22,2} \mathrm{H}_{34,2} \mathrm{~N}_{1,6} \mathrm{O}_{4,4}(\mathrm{COOH})_{2,5}$

$3,4 \quad \mathrm{C}_{117,1} \mathrm{H}_{140,8} \mathrm{~N}_{9,5} \mathrm{O}_{33,9}(\mathrm{COOH})_{9,1}$

$10,4 \quad \mathrm{C}_{6,1} \mathrm{H}_{12,1} \mathrm{~N}_{0,1}(\mathrm{COOH})_{1,9}$

$9,2 \quad \mathrm{C}_{4,0} \mathrm{H}_{8,1} \mathrm{~N}_{0,4} \mathrm{O}_{1,8}(\mathrm{COOH})_{1,4}$ 


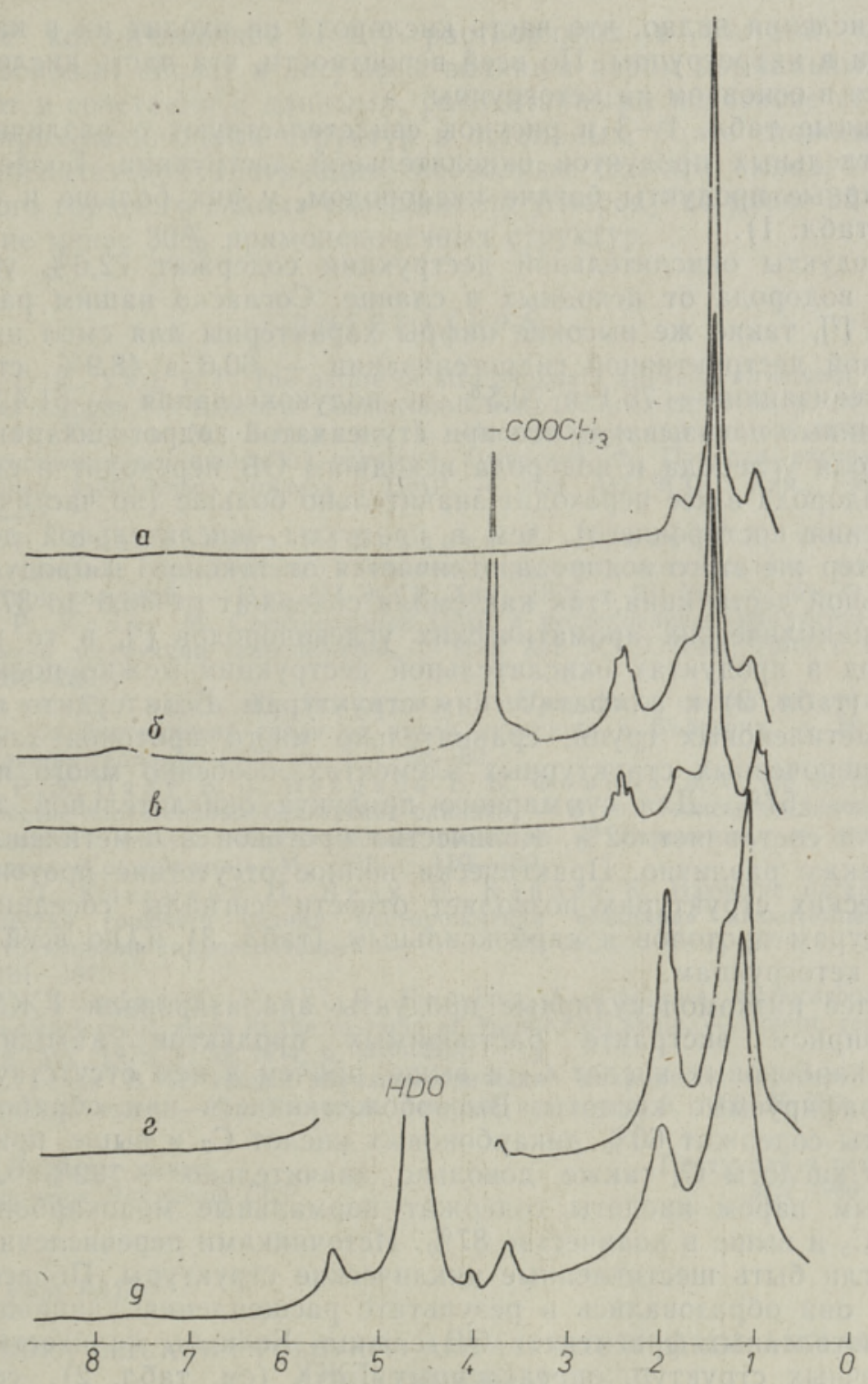

Спектры ${ }^{1} \mathrm{H}$ ЯМР: $a$ - битумоид, $\sigma$ - метиловые эфиры летучих с водяным паром кислот, в - индивидуальная пеларгоновая кислота $\left(\right.$ все в $\left.\mathrm{CDCl}_{3}\right), 2, \partial-$ эфирные экстракты растворимых и нерастворимых в азотной кислоте продуктов окисления соответственно (в виде калиевых солей в $\mathrm{D}_{2} \mathrm{O}$ ).

В отличие от ['], где содержание ионизированных протонов рассчитывали в предположении, что весь кислород находится в карбоксильных группах $\left(\mathrm{H}_{i} / \mathrm{H}=1 / 32(\mathrm{O} \% / \mathrm{H} \%)\right)$, в настоящем исследовании ионизированный водород в продуктах окисления-нитрования азотной кислотой определяли по разнице между общим кислородом и кислородом в азотсодержащих группах: $\mathrm{H}_{i} / \mathrm{H}=(\mathrm{O} \%-(32 / 14) \mathrm{N} \%) / 32 \mathrm{H} \%$. О том, что такое распределение до некоторой степени условно, говорят данные табл. 3 , где на примере ацетонового экстракта нерастворимых продук- 
тов окисления видно, что часть кислорода не входит ни в карбоксильные, ни в нитрогруппы. По всей вероятности, эта часть кислорода приходится в основном на кетогруппы.

Данные табл. $1-3$ и рисунок свидетельствуют о различном строении отдельных продуктов окислительной деструкции. Более низкомолекулярные продукты богаче кислородом, у них больше и отношение Н/C (табл. 1).

Продукты окислительной деструкции содержат $72,6 \%$ углерода и $61,7 \%$ водорода от исходных в сланце. Согласно нашим расчетам на основе [7], такие же высокие цифры характерны для смол низкотемпературной деструктивной гидрогенизации - 60,6 и 48,9\%, ступенчатой гидрогенизации - 75,1 и 70,5\% и полукоксования - 61,4 и $60,9 \%$. Эти данные показывают, что при ступенчатой гидрогенизации наибольшая доля углерода и водорода исходного ОВ переходит в смолу, причем водорода в нее переходит знанительно больше (но частично за счет внедрения постороннего), чем в продукты окислительной деструкции. Характер же этого водорода отличается от такового в продуктах окислительной деструкции, так как смола содержит от 36,6 до $37,8 \%$ монои полициклических ароматических углеводородов [7], в то время как водород в продуктах окислительной деструкции можно полностью отнести (табл. 2) к алифатическим структурам. Если судить по количеству метиленовых групп, сравнительно много протонов заключено в прямоцепочечных структурных элементах, особенно много их в битумоиде - $57 \%$. Для суммарного продукта окислительной деструкции их доля составляет $32 \%$. Количество протонов в $\alpha$-метиленовых группах также различно. Практически полное отсутствие протонов в ароматических структурах позволяет отнести сигналы соседних к этим структурам протонов к карбоксильным (табл. 3) и, по всей вероятности, к кетогруппам.

Более низкомолекулярные продукты анализировали ГЖХ-методом. В эфирном экстракте растворимых продуктов находится $86 \%$ $\alpha, \omega$-дикарбоновых кислот $\mathrm{C}_{7}$ и выше, причем в нем отсутствуют нехроматографируемые кислоты. Высвобождающиеся при обработке водой кислоты содержат $60 \%$ дикарбоновых кислот $\mathrm{C}_{7}$ и выше, причем количество кислоты $\mathrm{C}_{6}$ также довольно значительно - $32 \%$. Летучие с водяным паром кислоты содержат нормальные монокарбоновые кислоты $\mathrm{C}_{5}$ и выше в количестве $87 \%$. Источниками перечисленных кислот не могли быть шестичленные циклические структуры. По всей вероятности, они образовались в результате расщепления длинноцепочечных неразветвленных фрагментов ОВ сланца. Если бы количество длинноцепочечных структур, определенных ГЖХ (см. табл. 2), сопоставить с количеством тех же структур, полученных расчетным путем на основе сигнала с центром $\sim 1,25$ м. д., то последних бы оказалось значительно меньше. Это правомерно, и причину такого несовпадения раскрывает спектр ${ }^{1} \mathrm{H}$ ЯМР индивидуальной пеларгоновой кислоты (рисунок, в), где сигналы $\alpha$-и $\beta$-метиленовых и метильных групп относятся к прямоцепочечной структуре кислоты $\mathrm{CH}_{3}\left(\mathrm{CH}_{2}\right)_{7} \mathrm{COOH}$.

Если эту аналогию распространить на продукты окислительной деструкции в обратном порядке, то станет очевидно, что часть $\alpha$ - и $\beta$-метиленовых, а также метильных групп следовало бы отнести к прямоцепочечным фрагментам. Точный их учет пока невозможен из-за отсутствия удовлетворительной методики. Однако из сказанного следует, что относить сигналы $\alpha$ - и $\beta$-метиленовых и метильных групп только к непрямоцепочечным структурам, как это принято [ $\left.{ }^{1}\right]$, несправедливо. 
Данные количественной ГЖХ растворимых в азотной кислоте $\alpha, \omega$-дикарбоновых кислот и летучих с водяным паром нормальных жирных кислот в сочетании с данными, рассчитанными на основе спектров ${ }^{1} \mathrm{H}$ ЯМР прямоцепочечных структур в остальных, более сложных продуктах окислительной деструкции, позволяют сделать вывод, что ОВ мандраского горючего сланца содержит по углероду не менее $25 \%$ и по водороду не менее $30 \%$ прямоцепочечных структур.

\section{Л И ТЕРА Т У А}

1. Young, D. K., Yen, T. F. The nature of straight-chain aliphatic structures in Green River kerogen. - Geochim. Cosmochim. Acta, 1977, v. 41, N 10, p. 1411-1417.

2. Вески Р., Коэль М., Бондарь Е. Исследование продуктов ступенчатого азотнокислотного окисления керогена кукерсита. 2. Природа экстрактов по данным элементного анализа и ПМР. - Изв. АН ЭССР. Хим., 1980, № 1. c. $5-11$.

3. Вески Р., Филимонова Н., Бондарь Е., Лумисте Т., Фомина А. Исследование органического вешества диктионемового сланца окислением азотной кислотой. - Изв. АН ЭССР. Хим., 1979, т. 28, № 1, с. 32-39.

4. Вески Р., Коэль М. Спектроскопия ПМР в нсследованиях продуктов окислительной деструкции сапропелитов. - Изв. АН ЭССР. Хим., 1979, т. 28, № 4, c. $284-286$.

5. Ангелова Г., Тоцев Д., Минкова В. Природа и състав на органичната маса на битуминозни скали от някои находища в България. - Нефтена и въглищна геология, 1977 , кн. 7 , с. $53-60$.

6. Вески Р. Э., Палу В. А., Бондарь Е. Б., Фомина А. С. Об органическом веществе палеогеновых болгарских сланцев. - В кн.: Тезисы докладов VI Всесоюзного семинара «Органическое вещество в современных и ископаемых осадках (Седикахиты)». М., 1979, с. 119-120.

7. Наппа Л., Клесмент И., Винк Н., Кайлас К. Изучение органического вещества горючего сланца месторождения «Мандра» низкотемпературной деструктивной гидрогенизацией. - Изв. АН ЭССР. Хим., 1979, т. 28, № 3 , c. $191-197$.

8. Palu, V., B ondar, E., Veski, R., Fom in a, A. n-Alkanes, monocarboxylic and $\alpha, \omega$-dicarboxylic acids in the extracts of Mandra oil shale. - Compt. rend. Acad. bulg. Sci., 1979 , v. 32 , N 4 , p. $505-508$.

9. Михкельсон В. Я. Новый эбуллиометрический микрометод определения молекулярных весов. - Тр. Таллинск. политех. ин-та, сер. А, 1968, № 269, с. 59-69.
Институт химии
Академии наук Эстонской ССР
Поступила в редакцию
$31 / \mathrm{I} 1980$

\section{R. VESKI, Vilja PALU}

\section{MANDRA LEIUKOHA POLLVKIVI ALIFAATSETEST SIRGE AHELAGA STRUKTUURIDEST}

Elemendianalüüsi, gaasi-vedelikkromatograafia ja ${ }^{1} \mathrm{H}$ TMR-spektroskoopia abil on käesolevas uurimuses kindlaks tehtud, et Mandra leiukoha põlevkivi orgaanilise aine sirge ahelaga struktuurielementides on vähemalt $25 \%$ orgaanilise aine süsinikust.

\section{R. VESKI, Vilja PALU}

\section{ABOUT STRAIGHT-CHAIN ALIPHATIC STRUCTURES IN MANDRA OIL SHALE}

The products of nitric acid oxidation of Bulgarian oil shale were analyzed by means of elemental analyses, gas-liquid chromatography and ${ }^{1} \mathrm{H}$ NMR spectroscopy in order to determine the significance of the straight-chain aliphatic structures. Using the modified Young and Yen equation it was shown that no less than 25 per cent of organic carbon of Mandra oil shale is in straight-chain structures and that no less than 61.7 per cent of hydrogen in the organic matter of the said oil shale are aliphatic. 